\title{
Creative Self-Efficacy and Its' Relationship to Intellectual Stress among Gifted Students at the Jubilee School
}

\author{
Yahya Al-Dhaimat ${ }^{1, *}$, Noor Talal Albdour ${ }^{1} \&$ Mohamed Alshraideh $^{1}$ \\ ${ }^{1}$ Department of Special Education, Al-Hussein Bin Talal University, Jordan \\ *Correspondence: Department of Special Education, Al-Hussein Bin Talal University, Jordan. E-mail: \\ dhamity@gmail.com
}

Received: April 23, 2020

Accepted: June 8, $2020 \quad$ Online Published: June 20, 2020

doi:10.5430/wje.v10n3p208

URL: https://doi.org/10.5430/wje.v10n3p208

\begin{abstract}
Current study aimed at exploring Creative self-efficacy and its' relationship to intellectual stress among gifted students at jubilee school. Study sample consists of $(\mathrm{N}=100)$ of secondary intermediate stage students, Al-Zoubi scale (2014) to measure intellectual stress and Abbott scale (2010) to measure creative self-efficacy were used by researchers. Results reported that creative self-efficacy with its' two dimensions: creative thinking and creative performance among gifted students was in high degree, while intellectual stress level was in moderate degree. Study results also showed that no statistical differences attributed to class and sex variables, study revealed an inverse correlation between study dimensions, whenever efficacy increased in creative thinking and creative performance, intellectual stress is decreasing. Researchers recommend the importance of training gifted students' teachers on developing creative performance and thinking among gifted students, and provision therapeutic and counseling programs to decrease any psychological or intellectual stresses by holding workshops that expand enrichment and knowledge sides among teachers and gifted students.
\end{abstract}

Keywords: creative self-efficacy, gifted students, intellectual stress

\section{Introduction}

Developed countries have recognized that gifted and outstanding students are one of the pillars of their developmentrepertory as the former have enhanced the status of these countries to occupy prestigious global positions among countries in all fields. Therefore, developed countries devoted their efforts to care for them and their various aspects of thinking like creative thinking. Developed countries consider gifted and outstanding as one of the priorities of the learning and teaching process in various countries across the world. They, moreover, provide them with all possible material and moral facilities in order to create an environment suitable for creativity because these students represent the hope of their societies to progress and keep pace with rapid changes and developments in all aspects of life. Since the success of gifted students' performance is heavily influenced by their own mental and personal abilities, their beliefs about these abilities are as important as their role in achieving their own goals. They have also paid great attention to their educational, psychological, social and professional methods of care.

\subsection{Self-Efficacy vs. Creativity}

Although creative ability is necessary for creative expression, it is insufficient to produce a creative product. Creative expression-like other forms of behavior-is influenced by the individual's judgments about his ability to generate new ideas and useful creative products, and these self-judgments indicate the effectiveness of the self-creativity. Therefore, building creative self-efficacy is different from building general self-efficacy as is the case with creativity which differs from other fields (Puccio \& Cabra, 2011; Tierney \& Farmer, 2002).

Abbott (2010) identified two main areas of self-efficacy in creative thinking that represent the effectiveness of an internal mental state, such as expressing creativity through creative thinking skills, fluency and flexibility, detail, and originality that enable an individual to produce new and appropriate ideas. The other area is that of self-efficacy in creative performance that represents the effectiveness of the external social position, such as expressing creativity through the individual's internal and external systems that interact with each other during creative performance including: motivations, personality, mood, social context and others. 
Creativity can be a reaction to several environmental, mental, social and personal factors, and this interaction produces new and innovative solutions for different situations in any of the life or scientific areas, and what distinguishes these solutions is that they are more modern, authentic and have an influential social value. Such solutions are one of the processes that help man feel and perceive the problem, reveal weak areas, search for solutions, and test their authenticity; besides the possibility of making any adjustments to the results, and creating new ideas that are useful and compatible with the community when implemented (Tierney \& Farmer, 2002).

Ford (1996) pointed out in his theory of creative action that the belief in ability is one of the important factors that drive for creativity. He, furthermore, argued that the effectiveness of the creative self is similar - to some extent- to various concepts, such as: Creative Capability Beliefs and Creative Self-Image. The creative self-efficacy differs from other self-portraits such as self-esteem, and self-confidence that have broad and generalized feelings about the self, while the creative self-efficacy involves a specific judgment on the ability for creative work.

Although the origin of the concept of self-efficacy emerged from the social cognitive theory of Pandora, who tried to include this concept in some creative respects, Bandura did not clarify the nature of creative self-efficacy. Therefore, the research into the effectiveness of the creative self has evolved independently of Bandura on several issues, including : that the effectiveness of the self for the creative performance took place in multiple environments and this is not found in Bandura's studies, as it found multiple dimensions of the creative self-efficacy that tried to reveal whether the creative self-efficacy is able to form a concept of its own away from mixing it with the effectiveness of the general self, or considering it as one of its tasks, as well as a congruence between the concept of the creative self and the experiences of creators interviewed (Abbott, 2010; Yu, 2013).

Bandera (1997) asserts that individuals' perceptions of self-efficacy are the most influential perceptions of their daily lives and the most influential influence on their choice so that they are either passive or positive in their self-evaluation; thus, individuals become successful if they possess high self-efficacy or depressed if they possess low self-efficacy.

Gifted students have several mental attributes, including creative abilities, which are developed and refined by many means. The creative self-efficacy is defined as the beliefs of the individual about his creative abilities, and includes his beliefs about his creative thinking, in addition to his beliefs about his creative performance (Abbott, 2010). In addition, the creative self-efficacy provides influential and strong beliefs that work to enhance the level of perseverance among individuals and direct them towards the efforts that ultimately lead to an increased growth of their confidence in their creativity (Tierney \& Farmer, 2002; Farmer \& Tierney, 2017).

Gifted students also have a number of mental attributes, including creative abilities, but this ability alone cannot have creative productions because the belief that precedes an individual's performance motivates him to perform the performance that he aspires to. Creative self-efficacy provides strong and effective beliefs, which enhance the level of perseverance of individuals and direct them towards efforts that ultimately lead to an increased growth of their confidence in their creativity (Tierney \& Farmer, 2002).

Some researchers have discussed the differences in self-efficacy among gifted students according to variables such as grade and gender. The results of the studies on these variables have been contradictory as Alalusi (2001) did not find any fundamental differences in the self-efficacy attributed to the gender variable among university students. While Turki and Al-Qaisi (2012) found significant differences in self-efficacy attributed to the grade variable and that the differences were in favor of the gifted students in the tenth, ninth, and eighth grade students in Jordan compared to seventh grade students, however there were no fundamental differences in self-efficacy attributed to the gender variable.

The results of many researches in the field of the creative self-efficacy contributed to building and defining a special concept in theory and practice, and defining it for the creative self-efficacy, such as confirming the its association with the effort and risk necessary for creative expression, including expressing new and useful ideas, solutions and products. Lemons (2010) argued that "before being creative, we must know that we are creative, and that we have the ability to be creative, or have at least enough effort to become creative." He asserted that individuals need to be aware of their creativity, which represents how many attempts an individual has to be more creative.

The definitions of creative self-efficacy vary. Bandura (1997) reorganized the relationship between self-efficacy and creative behavior. He argued that creativity is one of the sublime forms of human expression, which includes the reorganization of knowledge in new forms of thinking and behavior, as it requires a great deal of cognitive facilities to override traditional ways of thinking to arrive at new ideas and innovative knowledge. Furthermore, he added that creativity requires a sense of effectiveness and perseverance and to continue producing innovative outputs. 
Researchers argue that the creative self-efficacy is an extension of the creativity of the general self in addition to his belief in his ability to successfully perform distinguished creativity in a work, study or any other environment.

Bandura (2007) also described self-efficacy as a motivational condition in which the individual's self-esteem is measured through carrying out certain actions to achieve some of his goals. Self-efficacy is not concerned with what an individual possesses, rather is concerned with his beliefs about what he can do, which represents the knowledge domain of operations.

Similarly, Phelan (2001) defined self-efficacy as the individual's beliefs about his ability and creative energy to achieve the desired improvements, innovations and changes.

Like Bandura, Tierney and Farmer (2002) define self-efficacy as the belief of the individual to achieve creative outcomes, whereas Laws (2003) defined it as an individual's belief in his ability to be creative in a particular situation. Abbott (2010a) defined it as the beliefs of an individual about his creativity including his beliefs about his creative thinking and creative performance. Researchers believe that all definitions focused on the individual's beliefs concerning his ideas and outstanding performance.

Several studies were conducted on the subject of the creative self-efficacy in different regions of the world, but the researcher did not find Jordanian or Arabic studies on the creative self-efficacy and its relationship to intellectual stress, and this may be due to the novelty of the topic. Hence, the study of Beghetto (2006), which was conducted in North America on a large sample consisting of (1322) male and female students, revealed that the creative self-efficacy of females was lower than that of males. The study also showed that there is a positive correlation between the creative self-efficacy and each of the students 'attitudes towards mastery, their beliefs about their creative performance, and the feedback from their teachers about this performance. Moreover, it pointed out that students who have higher levels of creative self-efficacy were better than those with lower levels in all subjects, were more involved in academic and group after-school activities, and were more determined to enroll in universities after finishing their school. Gibbs (2009) found that progress in life predicts a decrease in the creative self-efficacy among (232) members of societies in America, while it did not find a statistically significant predictive relationship attributed to gender variable in the creative self-efficacy.

The study of Rogelio and Jadith (2017) aimed to study the role of internal and external organization and boredom as precedents of creative self-efficacy and to assess the effect of creative self-efficacy on differentiated thinking among children. The results of the study showed a positive effect of internal and external organization on self-creativity and efficiency. Likewise, in internal organization, students had a negative relationship with boredom.

The study of Babaket al. (2008) also aimed to examine the relationship between the state of mental health and its relationship to cognitive pressure and perceived self-efficacy among male adolescent students. The study sample consisted of 866 students from high school students. The results of the study revealed that self-efficacy affects mental health and the response to stress among adolescents. It also indicated that those with high self-efficacy are able to face the stress and that their mental health is good, while those who have less self-efficacy find it difficult to deal with stress, which leads to an increased exposure to anxiety and mental distress.

Iglesia et al. (2005) conducted a study that aimed to identify the relationship between self-efficacy and both anxiety and mental pressure among a sample of university students, the sample of the study consisted of 136 students. The study showed that there is high self-efficacy among students, and that those with high self-efficacy are able to face the stress and that their mental health is good.

A study conducted by $\mathrm{Li}$ and $\mathrm{Wu}$ (2011) aimed to reveal the structural relationship between optimism, creative self-efficacy and creative behavior and to understand the effect of the underlying potentials of university students. The study sample consisted of (970) university students in Taiwan. The results of the study showed statistical significance that creative self-efficacy mediates the relationship between creative behavior and optimism.

The study of Chin (2013) also examined the detection of a relationship between creative self-efficacy, creativity and professional self-management. The study sample consisted of (158) university students in China. The results of the showed that there are two factors for the creative self-efficacy: the desire for creativity in addition to creative behavior, as well as professional self-management through the creative self-efficacy. The results also showed a positive correlation between creative self-efficacy and creativity.

As for the study of Al-Ali and Sahloul (2004), it aimed to identify the relationship between self-efficacy and motivation for achievement among students in the city of Sanaa, and to examine the effects of each of them and the interaction between them in the academic achievement of students. The study sample consisted of 1025 male and female students of second secondary grade. The results of the study indicated that there is a statistically significant 
positive correlation between self-efficacy and motivation for achievement among the study sample. It also pointed out that there is no statistically significant difference in academic achievement of students due to the levels of self-efficacy or the interaction between self-efficacy and motivation for achievement.

Bandura et al. (1992) conducted a study aimed at examining the effect of self-efficacy beliefs in achieving personal goals and motivating academic achievement, on a sample of high school students. The results of the study indicated that the individual's beliefs about his self-efficacy and self-learning highly influence the motivation for academic achievement and their ability to achieve personal goals.

As contemporary life has become a source of many stressful and psychological crises that have arisen as a result of various factors related to the reality of individuals and their future concerns, studies are of the opinion that the extent of a person's feeling of happiness depends on the extent of his ability to face stressful life situations that cannot be eliminated or overcome. In many cases, the individual seeks to coexist, adapt to or escape from and try to forget about them. The more complicated life and its relationships are intertwined, the more practical exertions increase and the causes and its boundaries multiply, intellectual stress arises with the coherence of internal and external factors, and its signs appear in an increasing lack of performance and a feeling of malaise and pain. In addition to physiological changes such as high or low blood sugar and accumulation of toxins such as lactic acid Muscle Carbon Dioxide (Moussaoui, 2012).

The concept of intellectual stress in psychology is used to show situations in which an individual is under emotional, mental or physical stress. If such stresses are prolonged, the individual is occupied with aversion and non-apprehension and thus leads to psycho-somatic disorders such as anxiety and depression. Although stress has physical and psychological damage which Celli calls (the spice of life) and believes that its goal is (death). This means that the stresses to which the individual is subjected compel him to adapt to the circumstances surrounding him and restore conformity with his social environment, thus leading him to a state of sound mental health, because each individual seeks to adapt during his life (Eaton, 1980: 83).

Intellectual stress is one of the most complex psychological and social phenomena, and it is noticed that it is increasing with the speed of technological progress. Some researchers even see it as a recognition of the gap between developed and third-world countries (Moussaoui, 2012).

Despite the many definitions of intellectual stress, they agree on key concepts. Flolkman and Lazarus (1990) defined intellectual stress as a state of resentment and mental manipulation resulting from positive or negative intellectual stimulants that the individual's abilities cannot cope with.

Likewise, Bee and Bjorklund (2004) defined intellectual stress as a dynamic interaction between the external factor facing the individual at a given time and place and the physical and mental defenses one uses to face intellectual stress. Thus, the individual becomes exposed to physical risks depending on the state of his psychological structure and physical and social context. Researchers believe that intellectual stress has negative consequences on the physical and psychological aspects.

On one hand, the intellectual stress results in many psychological, cognitive and behavioral effects that leave negative effects on the student's personality and motivation. As to the psychological effects, stressful situations could affect the psychological health of the individual, thus leaving negative feelings including frustration, depression, irritability, mood swings, nervousness, anger and aggression, anxiety, loss of security, low self-esteem, confusion, delusion, boredom, low motivation, feelings of incompetence, ineffectiveness and a feeling of psychological burning, and the feeling of dullness. There are cognitive effects represented by cognitive disorders such as difficulty in concentration, poor memory and difficulty in making decisions, disturbance in thinking, the obsession of the mind with one idea, and incorrect decisions. David Fontana conducted a study which asserted this. The study also pointed to some cognitive effects related to exposure to acute stresses that appear in less attention; thus, leading to less focus and weak observation which in turn results in increasing the capacity disturbance, and the individual relatively loses control of thinking or what he thinks or what is said. Consequently, short and long-term memory deteriorates, and the memory extent and recalling and recognizing familiar things decrease. It becomes difficult to predict the speed of response, the actual response speed decreases, and attempts to compensation may lead to hasty decisions. The rate of errors in cognitive tasks and treatments increases, and the decisions of the individual become questionable, the forces of organization and long-term planning deteriorate, so the mind becomes unable to accurately assess current conditions or predict future sequences. In addition, intellectual disturbances and illusion increase, so the selection of reality becomes less efficient, the objective elements of criticism decrease, and patterns of thinking become turbulent, irrational or illogical (Fatiha, 2008). 
On the other hand, Fatiha (2008) argues that the behavioral effects are unjustifiable mistrust of others, forgetting or cancelling appointments with a short notice, hedging and meshing mistakes of others, adopting a defensive trend in relations with others, and interacting with them in an auto way. They also could be represented in a low productivity, high degree of discretion, increased number of errors and delays, absenteeism, dependence on tranquilizers, over-smoking or eating, and alcohol abuse or addiction.

The aim of the Al-Zubeidi study (2015) was to identify the intellectual stress of middle-school students attributed to the variable of gender (male, female) and to identify the fear of failure in middle-school students. The study population consisted of (400) students. The study found that middle school students suffer of intellectual stress and that they fear of failure. The results of the study also found that females are more fearful of failure than males, and that there is a correlation between intellectual stress and fear of failure.

Hassan's study (2006) aimed to identify stress and the differences in stress according to the gender variable and the interaction between them among students of the College of Education at Al-Mustansiriya University. The study was conducted on a sample of (161) students. The results of the study indicated that the participants suffered of high stress, while there was no major effect for both the gender and grade variables, and there was no interactive effect for these two variables on the level of stress among the study sample.

As for Al-Najjar's study (2012), it aimed to identify the level of psychological tension, and both self-efficacy and social support for high school students, and the actual sample consisted of (500) male and students. The results of the study pointed to the existence of a statistically significant negative correlation between psychological tension and self-efficacy and social support among high school students; moreover, the results showed statistically significant differences in psychological tension attributed to the gender variable in favor of females.

Al-Omari's study (2012) verified that there is a relationship between each of the school psychological stress, academic achievement, and mental health among a sample of (428) of high school students in Al-Leith governorate. The results of the study showed that school stress, academic achievement, and mental health were of average degree, as well as a negative correlation between the levels of school psychological stress, academic achievement, and the mental health of students. The results also pointed to statistically significant differences among the mean scores of those of high school psychological stress, and the mean scores of those of low school psychological stress in relation to the academic achievement and mental health in favor of low psychological school stress.

\subsection{Study Problem}

The problem of this study stems from several factors, the most important of which is that the Arabic studies that dealt with the creative self-efficacy among the gifted and their relationship to intellectual stress are few according to the researchers' knowledge, and they represent the beliefs of the individual about his creative capabilities and affect his performance.

Throughout the last twenty years and in light of technological and cognitive development, the world has started to move towards creativity and innovation, being one of the pillars of economic growth and scientific and educational production. Studies related to factors that enhance or hinder creative efforts have developed, the most important of which is the creative self-efficacy. Building the creative self-efficacy has important implications for understanding creativity and innovation, and therefore it is worthwhile to study it among the gifted ones, in particular, and review how to measure and study its relationship with some variables. The researchers have identified the variable of intellectual stress in this research.

The concept of creative self-efficacy is one of the new concepts in psychology and in the fields of gifted studies, where libraries lack studies related to them in this field, as it wasn't the center of attention of researchers. Based on the researchers' knowledge, this concept has not been studied in relation to the study variable of (intellectual stress) in Arab society in general. Therefore, and due to the contemporary trends to become familiar with the characteristics and capabilities of the gifted and their relationship to each other, the problem of study is determined in its attempt to reveal the relationship between the creative self-efficacy and the intellectual stress of gifted students, and accordingly, it is hoped that this study will take a step towards adding new knowledge in the field of gifted education.

\subsection{Research Questions}

To achieve this, the researchers try to answer the following questions:

First: What is the degree of the creative self-efficacy among secondary stage gifted students?

Second: What is the degree of intellectual stress among secondary stage gifted students? 
Third: Is there a statistically significant correlation between the creative self-efficacy and the intellectual stress among secondary stage gifted students?

Fourth: Are there statistically significant differences between the average degrees of the creative self-efficacy due to the gender and grade variables among secondary stage gifted students?

Fifth: Are there statistically significant differences between the average degrees of intellectual stress attributed to the gender and grade variable among secondary stage gifted students?

This study aimed to reveal the nature of the relationship between the creative self-efficacy and the intellectual stress among secondary stage gifted students, in order to develop their cognitive abilities and benefit from their creative self-efficacy.

\subsection{Importance of the Study}

The importance of the study stems from its attempt to reveal the nature of the relationship between two variables that were not previously studied in the Arab environment, according to the researchers' knowledge, and to provide the Arab library with theoretical frameworks to study these two variables in new environments. The study dealt with a grade of students rarely addressed by Arab studies that could provide a quality contribution in the research field and an opportunity to design training programs or strategies that address the creative self-efficacy in order to be developed among gifted students.

\section{Study Methodology}

In order to achieve the objectives of the study, the descriptive correlative approach was adopted, considering the nature of the study problem, the type of variables and the characteristics of the study sample.

\subsection{Study Population}

The study population consisted of (423) male and female students gifted students in the secondary stage at the Jubilee School in Amman. Sample was selected by intentionality method for females $\backslash$ males gifted students who were classified by education administration after they had passed gifted scale.

\subsection{Study Sample}

The study tools were applied to (115) male and female students. After reviewing the tools and excluding the incomplete items of the questionnaire, the number of students became (100) male and female students, and this sample is considered representative of the total study population.

\subsection{Study Tools}

Researchers used the following tools:

\subsubsection{Creative Self-Efficacy Scale}

The scale was designed by Abbott (2010). It consists of 21 items distributed into two dimensions:

The first dimension: the self-efficacy in creative thinking, represented in items 1 to 12 , and the second dimension is the creative self-efficacy in creative performance, represented in items 13 to 21 .

The goal of the scale was to determine the level of creative self-efficacy that prevailed among members of the study sample. Likert five-point scale was used: always, often, sometimes, rarely, never.

\subsubsection{The Intellectual Stress Scale}

The researchers used the questionnaire expressed by (Al-Zoubi, 2014) consisting of 21 items, distributed into two dimensions: feeling fatigue and mental fatigue, and feeling powerless). The Likert five-point scale was used: always, often, sometimes, rarely, never.

\subsubsection{Validity of the Scales}

To verify the validity of the two scales, the correlation coefficient was calculated between each of the questionnaire items within the two dimensions of each scale using the Pearson coefficient correlation. Therefore, results of the validity and reliability of the two scales in the original studies confirm that they are suitable for the objectives of the present study. The researchers found the correlation between the fields of the main study dimensions (the creative self-efficacy and the intellectual stress) and the items in order to ensure its reliability. The results of the study showed that there is a positive correlation between the fields of intellectual stress with the items of each dimension at the level of $(a \leq 0.01)$, where correlation coefficients ranged between $(* * 0.294)$ and $(* * 0.670)$. The results also 
revealed that there are correlation coefficients concerning the fields of self-efficacy with the items related to each dimension as they ranged between $\left({ }^{* *} 0.266\right)$ and $\left({ }^{* *} 0.628\right)$ at the significance level of $(\mathrm{a} \leq 0.01)$, and that these results confirmed the validity of the tool and the reliability of its items for the objectives of the current study. The researchers also verified the external validity by sending it to (10) specialists in the field from Jordanian universities and others for its arbitration. The results of the arbitration indicated that the two tools were suitable for the objectives of the study. The percentage of agreement on the two scales was high, and there was no change in the items in terms of number and formulation.

\subsubsection{Reliability of the Scales}

The reliability of the tools used in the current research to answer the study questions was achieved through the use of pre-designed and used scales in previous studies, where their validity was verified before their use, and the results of the arbitration indicated that the two tools were suitable for the objectives of the current study.

Although the tool was extracted from previous studies, this proves its validity and reliability, the researchers calculated the reliability of the tool in the current study to also verify its validity. The tables showed that the values of the validity of the creative self-efficacy and the intellectual stress in both dimensions, which were all of high values and these were considered highly accepted values, as the total value of the intellectual stress was (0.812), and these were considered high and indicated the reliability of the tool used in the research, and the reliability of the creative self-efficacy and its dimensions was found through Cronbach Alpha values, where the total value was (0.918), which was also considered high value. These results confirm the reliability of the tool and its suitability to achieve the goals of research.

\section{Results and Discussion}

To answer the first question, mean and standard deviations of the dimension of the creative self-efficacy were calculated as in Table 1.

Table 1. The Means and Standard Deviations for Student's' Responses to Creative Self-Efficacy Scale

\begin{tabular}{lcc}
\hline Domains & M & SD \\
\hline Creative thinking & 3.7904 & .45343 \\
Creative Performance & 3.9507 & .49793 \\
Total & 3.8591 & .42380 \\
\hline
\end{tabular}

To answer the first question, mean and standard deviations of the dimension of the creative self-efficacy were calculated, as most of the answers ranged between high and very high. This indicates the degree of the high creative self-efficacy of gifted students in the Jubilee School. The average creative performance was higher than the average of creative thinking with a slight difference as in Table 1 where it is noticed that the field of creative performance came first with an average of (3.9507), followed by the field of creative thinking with an average of (3.7904). The highest average of the items of the creative self-efficacy in creative thinking was item (7), "I think of finding convincing ways to defend my ideas that are not familiar to others by starting from what they already know," with an average of (4.16). As for the item that got the lowest average concerning the creative self-efficacy in creative thinking was item (9), "I tell other people's stories based on their dreams completely even if they are incomplete," with an average of (3.09). Even though the mean of all itemswas high which indicates that gifted students have creative thinking skills. The highest mean of the items of the creative self-efficacy in creative performance was item (13), which is "I understand the thing that I want to do," with an average of $(4,48)$. The item that scored the lowest mean in creative self-efficacy in creative thinking was item (21), "I keep my questions about some things even if I have been working on them for a long time," with an average of $(3,48)$. However, the mean of all items was high, and this indicates that gifted students have creative performance skills. The results also showed that gifted students in the Jubilee School have a high level of creative self-efficacy, which comprised of the self-efficacy in creative thinking and the self-efficacy in creative performance, which scored very high values, and these results were in agreement with the study of Al-Zoubi (2014): which found a high level of creative self-efficacy among gifted students and their teachers in Jordan. Similarly, the study conducted by Khalaf (2016) showed that the self-efficacy level was high among gifted students in Jordan. Likewise, Salem (2009) revealed that female students were found to have a high level of self-efficacy. Consequently, studies found that self-efficacy had a relationship and impact on some factors and variables, such as creativity and professional self-will, (Chin, 2013), and on optimism and creative behavior (Li \& Wu, 2011). 
The researchers attribute these results to the great attention paid by the Jubilee School to develop the teaching process for gifted students to suit their interests. The school undertook several training programs on many important modern strategies such as brainstorming strategy and developing critical and creative thinking. It also provided the appropriate physical and educational environment in order to help these students develop and refine their creative thinking in addition to the special care of the parents and the high expectations contributed to the creative self-efficacy. Moreover, the motivation of the students themselves, which is more important in proving themselves and achieving their goals, all this contributed to the high values of the creative self-efficacy. The belief in ability is one of the most important factors that contribute to the motivation for creativity, the individuals' perceptions of their effectiveness are the most influential in their daily lives, and the choice to be negative or positive in their self-evaluation; therefore, individuals become successful if they have high self-efficacy or depressed if they have low self-efficacy. The creative self-efficacy appears as a result of the availability of strong and effective beliefs that enhance the level of perseverance and self-confidence. To answer the second question, the mean and standard deviations were extracted as in Table 2.

Table 2. The Means and Standard Deviations for Student's' Responses to Intellectual Stress Scales

\begin{tabular}{lcc}
\hline Domains & $\mathrm{M}$ & $\mathrm{SD}$ \\
\hline Feeling sick and tired & 2.8402 & .61197 \\
Feeling powerless & 3.2845 & .75351 \\
Total & 3.0624 & .60489 \\
\hline
\end{tabular}

To answer the second question, mean and standard deviations of the intellectual stress dimension were calculated since most of the answers were average, and this indicates an average degree of intellectual stress among gifted students in the Jubilee School. The average of feeling helpless was higher than that of feeling fatigue as shown in Table 2, where it is noted that the dimension of feeling helpless came first with an average of (3.284) followed by that of feeling fatigue with an average of (2.840). The highest average of the items of the intellectual stress in feeling fatigue was item (23), "I suffer from persistent fatigue due to the large number of lessons," with an average of (3.680). As for the item that got the lowest average of the intellectual stress in feeling fatigue was item (30), "My relationships with my colleagues are bad," with an average of (2.05). However, the items averages ranged between medium and high, and this indicates that gifted students have intellectual stress. The highest average of the items of intellectual stress in the feeling of helpless was (34), "I'm not convinced with some subjects that I study," with an average of (3.83). Whereas, the lowest item of intellectual stress in the feeling of helpless was item (41), "I feel sad and hopeless" with an average of (2.56). Nevertheless, the mean of all items was average, and this indicates that gifted students have moderate intellectual stress.

The researchers believe that this result is reasonable, as there must be a kind of intellectual stress resulting from hard work and the desire to be creative in order to reap the fruits of what has been accomplished, and this constitutes a driving force towards creative performance. However, there is a clear negative relationship where the greater the self-efficacy is, the less the intellectual stress will be. The results of Babak's study (2008) showed that those who have high self-efficacy could manage stress, and that their psychological health is good, while those who have less self-efficacy, have difficulty in dealing with stress, which leads to increased anxiety or exposure to psychological stress. Lemons (2010) believes that the creative self-efficacy is related to the effort and risk necessary for creative expression, and the result of this study is consistent with the study of Iglesia (2005) in terms of a negative correlation between self-efficacy, psychological stress and anxiety among gifted students.

Table 3. Correlations Coefficient among Variables (Creative Self-Efficacy. Intellectual Stress)

\begin{tabular}{cc}
\hline Doman & intellectual stress \\
\hline Creative Self-efficacy & $* *-.0118$ \\
\hline
\end{tabular}

To answer the third question, the Pearson correlation coefficient was used. It is found that there is an inverse correlation between the two dimensions of the study, and this is shown in Table 3 above. However, this relationship is not statistically significant at the level of $(a \leq 0.05)$ where the greater the creative self-efficacy is, the less intellectual stress will be. The researchers believe that this result is reasonable, as the more efficacy in thinking and creative performance is, the more positive it is for the person to be motivated, to feel good and to achieve what he 
seeks to; thus, this contributes greatly to a state of complacency and relaxation. This outcome is consistent with the study of Iglesia (2005) in terms of a negative correlation between self-efficacy and psychological stress and anxiety of gifted students.

Table 4. The Means and Standard Deviations for the Students' Responses to the Creative Self-Efficacy Scale Based on Their Gender and Grade

\begin{tabular}{llll}
\hline Grade & Male & Female & Total mean \\
\hline Tenth & 3.704 & 3.874 & 3.778 \\
Eleventh & 3.848 & 4.103 & 3.943 \\
Twelfth & 3.875 & 3.830 & 3.829 \\
Total mean & 3.8112 & 3.9274 & 3.8591 \\
\hline
\end{tabular}

To answer the fourth question, "are there any statistically significant differences between the average degrees of the creative self-efficacy due to the gender and grade variables among gifted students?" The mean scores of the sample members was calculated concerning the scale of self-efficacy according to the gender and grade variables as shown in table 4 above. The one-way analysis of variance was performed to indicate the differences between the mean scores of the creative self-efficacy according to the gender and grade variables and their interaction, table 5 illustrates this.

To answer the fourth question, "are there any statistically significant differences between the average degrees of the creative self-efficacy due to the gender and grade variables among gifted students?"One-Way ANOVA variance analysis was used to test the differences between the mean of the answers attributed to the gender and grade variables. The results in table 5 indicate that there are no differences between the mean of the answers attributed to the gender and grade variables, and that there is an interaction between them at the significance level of $(a \leq 0.05)$.

Table 5. One-Way ANOVA Analysis for Differences in Students' Creative Self-Efficacy Based on Their Gender and Grade

\begin{tabular}{llllll}
\hline Variable & Sum of squares & d.f & Mean of squares & F & Sig. \\
\hline grade & .550 & 2 & .275 & 1.558 & .216 \\
Gender & .378 & 1 & .378 & 2.141 & .147 \\
Grade $\times$ Gender & .376 & 2 & .188 & 1.066 & .349 \\
Error & 16.070 & 91 & .177 & & \\
\hline
\end{tabular}

The researchers attribute the lack of differences among the mean of the answers in the study population to the great development of knowledge in the teaching methods used to develop gifted students that occurred in previous years, and the educational policy followed by the Jubilee School is one, where all students, male and female, receive the same educational methods and strategies for the different grades levels, in addition to the process of selecting the best students for this school at the state level and this contributed to the lack of individual differences due to the gender and grade variables. In addition to the desire for achievement and motivation, the competitive atmosphere among students at all grades and age is one of the reasons that contributed to the lack of differences attributed to the study variables. The results of the study concorded with the studies of Turki and Al-Qaisi (2012) and Gibbs (2009), regarding the grade variable as there were no statistically significant differences. Whereas, the study disagreed with those of Turki and Al-Qaisi (2012) and Beghetto (2006) regarding the gender variable where there were no statistically significant differences.

It is clear from Table 5 that there are no statistically significant differences at the level of $(a \leq 0.05)$ in the degrees of the creative self-efficacy among gifted students in the secondary stage according to the variables of gender, grade, and interaction between them; however, referring to Table 4 that shows the mean, it is evident that there are apparent differences in the creative self-efficacy with regard to the variables of the study, where the differences are in favor of the eleventh grade students with regard to the variable of the grade. The researchers argue that the result is logical since students enter the school in the tenth grade and this is a new environment for them. In order to adapt to the school's regulations, instructions and policies, students need time to adapt to the school environment. As for the gender variable, the differences are in favor of the females, and researchers attribute this to female distinction in the academic aspect at the Kingdom level regarding national or international exams. 
To answer the fifth question, "Are there statistically significant differences between the average degrees of intellectual stress attributed to the gender and grade variables for gifted students?" The mean of the respondents scores was calculated on the scale of intellectual stress according to gender and grade variables as shown in table 6. One-Way ANOVA variance analysis was performed to indicate the differences between the mean levels of intellectual stress degrees according to gender and grade and the interaction between them as shown in table 7 .

Table 6. The Means and Standard Deviations for the Students' Responses to the Intellectual Stressscale Based on Their Gender and Grade

\begin{tabular}{|c|c|c|c|c|}
\hline Grade & Gender & Male & Female & Total mean \\
\hline Tenth & & 2.8306 & 3.087 & 2.953 \\
\hline Eleventh & & 3.030 & 3.087 & 3.051 \\
\hline Twelfth & & 3.178 & 3.267 & 3.113 \\
\hline Total Mean & & 3.062 & .3158 & .3994 \\
\hline
\end{tabular}

To answer the fifth question, "are there statistically significant differences between the average degrees of intellectual stress attributed to the gender and grade variables for gifted students?" One-Way ANOVA variance analysis was used to test the differences between the mean of the answers attributed to the gender and grade variables. The results in table (6) indicate that there are no differences between the mean of the answers attributed to the age and grade variable, and that there is an interaction between them at the significance level of $(a \leq 0.05)$.

The researchers attribute the lack of differences among the mean of the answers in the study population to the high self-efficacy of all students at different grade levels. As a result of their high self-efficacy, they contributed significantly to facing intellectual stress. This result disagrees with the studies of Al-Zubaidi (2015) and Al-Najjar (2006), regarding the gender variable, as these studies found differences in the gender variable in favor of females. The results of some studies showed that those who have high self-efficacy could face the pressures and that their psychological health is good for them. Whereas those who show less self-efficacy, face difficulties dealing with or facing pressure, thus, leading to increased tension and exposure to anxiety and psychological stress. The creative self-efficacy is shown to provide effective and strong beliefs, which work to enhance the level of perseverance among individuals, and direct them towards the efforts that ultimately lead to an escalating growth of their confidence as have the creative capabilities.

Table 7. One-Way ANOVA Analysis for Differences in Students' Creative Self-Efficacy Based on Their Gender and Grade

\begin{tabular}{llllll}
\hline Variable & Sum of squares & d.f & Mean of squares & F & Sig. \\
\hline grade & .781 & 2 & .391 & 1.062 & .350 \\
Gender & .631 & 1 & .631 & 1.715 & .194 \\
Grade $\times$ Gender & .192 & 2 & .096 & .261 & .771 \\
Error & 33.456 & 91 & .368 & & \\
\hline
\end{tabular}

It is clear from table (6) that there are no statistically significant differences at the level of $(0.05 \geq \alpha)$ in the degrees of intellectual stress among the gifted students in the secondary stage attributed to the gender and grade variables, and the interaction between them; however, by referring to table (7), that clarifies the averages, it is shown that there are apparent differences in intellectual stress in relation to the study variables, where the differences are in favor of twelfth grade students with regard to the variable of the grade. The researchers argue that students are subjected to intellectual stress as it is a transitional stage for the university, and thus suffer from intellectual stress for their desire to obtain a distinct level of academic achievement. Furthermore, the high expectations of their families at the end of the school stage causes a great burden on students, thus leading to the cause of intellectual stress. This result disagreed with the studies of Al-Zubaidi (2015), Al-Najjar (2006), and Hassan (2006) in terms of the lack of differences due to the grade variable. The result of this study also agreed with Al-Zubaidi (2015) and Al-Najjar (2006), regarding the gender variable, where these studies found differences in the gender variable in favor of females, and disagreed with the study of Hassan (2006) where no differences are attributed to the gender variable.

\section{Conclusions and Recommendations}

It could be concluded from the results of the study that the creative self-efficacy among gifted students is high among 
all students and at different grade levels. It is higher for females than for males, and this may lead to the emergence of two sub-conclusions; the first is related to the creative self-efficacy, where the greater the creative self-efficacy is, the less intellectual stress is. The second is that those who possess high self-efficacy could face the pressures and difficulties they face. It is worth noting that this study deliberately measured the creative self-efficacy and its relationship with intellectual stress, since the assessment of the performance is less likely to be overstated than the assessment of thinking. Students' reality in assessing their creativity may be the result of their being subject to many positive and negative experiences that may have contributed to shaping their creative self-efficacy. Based on the most important results of this study, it recommends the following:

- Considering the measurement of the creative self-efficacy while selecting gifted students at the Jubilee School.

- Training gifted students on the means to raise their level of effectiveness.

- Training students on the best strategies for dealing with intellectual stress.

- Conducting more studies about the creative self-efficacy among gifted students, such as:

- Changes in the creative self-efficacy among gifted students according to age variable.

- Factors affecting the creative self-efficacy among gifted students.

-What are the appropriate strategies to deal with intellectual stress?

\section{References}

Abbott, D. (2010). Constructing a creative self-efficacy inventory: A mixed methods inquiry (Unpublished doctoral thesis). Nebraska University, USA.

Al-Ali, N., \& Sahloul, M. (2004). The relationship between self-efficacy and effectiveness of achievement and their impact on academic achievement among high school students in Sanaa governorate. Umm Al-Qura University Journal for Educational, Social and Human Sciences, 18, 91-130.

Al-Alusi, A. (2001). Self-efficacy and its relationship to self-esteem among university students (Master Thesis is Published). University of Baghdad, Baghdad, Iraq.

Al-Musawi, Q. (2012). Intellectual stress and its relationship to some personality traits of graduate students (Unpublished Master Thesis). Al-Mustansiriya University.

Almushikhi, G. (2009). Future anxiety and its relationship to both self-efficacy and the level of ambition of a sample of students the University (Unpublished PhD thesis). Um Al-Qura University, Makkah Al-Mukarramah, Saudi Arabia.

Alnajaru, F. (2012). Psychological tension and its relationship to both self-efficacy and social support among high school students (Master's thesis). Faculty of Education, Department of Psychology, Islamic University, Gaza: Palestine.

Al-Omari, M. (2012). School psychological stress and its relationship to academic achievement and the level of mental health of a sample of high school students in Al-Layth governorate (Master's degree). College of Education, Umm Al-Qura University: Saudi Arabia.

Babak, M. et al. (2008). Perceived stress, self -efficacy and Its Relation to Psychological Well-Being Status in Iranian Male high school students. Journal of social and Behavior Personality, 36(2), 257-266. https://doi.org/10.2224/sbp.2008.36.2.257

Bandura, A. (1997). Self-efficacy determinants of anticipated fears and Calamities. Journal of Personality and Social Psychology, 45, 464. https://doi.org/10.1037/0022-3514.45.2.464

Bandura, A. (2007). Much ado over a faulty conception experimentation. Journal of Social Psychology and Clinical, 26(6), 641-658. https://doi.org/10.1521/jscp.2007.26.6.641

Bee, H., \& Bjorklund, B. (2004). The Journey of Adulthood (4th ed.). New Jersey: Pearson education.

Beghetto, R. (2006). Creative self-efficacy: Correlates in middle and secondary students. Creativity Research Journal, 18(4), 447-457. https://doi.org/10.1207/s15326934crj1804_4

Chan, D. (2007). Positive and negative perfectionism among Chinese gifted students in Hong Kong: Their relationships to general self-efficacy and subjective well-being. Journal for the Education of the Gifted, 31(1), 125-131. https://doi.org/10.4219/jeg-2007-512 
Chin, Y. (2013). The relationship between undergraduate students' creative self-efficacy, creative ability and career self-management. International Journal of Academic Research in Progressive Education and Development, 2(2), 181-193.

Farmer, S., \& Tierney, P. (2017). Considering Creative Self-Efficacy: Its Current State and Ideas for Future Inquiry. In Maciej Karwowski \& James C. Kaufman (Eds.), Explorations in Creativity Research (pp. 23-47). Academic Press. https://doi.org/10.1016/B978-0-12-809790-8.00002-9

Fatiha, B. Z. (2008). Personality patterns and its relationship to intellectual stress level, symptoms, resources, and coping strategies, a field study on a sample of civil protection workers ( $\mathrm{PhD}$ thesis). University of MentouriConstantine.

Flolkman \& Lazarus. (1990). Relation appraisal's coping and adjustment. Journal of Scounsling Psychology, 40, 11.

Ford, M. (1996). A theory of individual creative action in multiple social domains. Academy of Management Review, 21(4), 1112-1142. https://doi.org/10.5465/amr.1996.9704071865

Gibbs, S. (2009). Exploring the influence of task specific self-efficacy on opportunity recognition perspectives and behaviors. Frontiers of Entrepreneurship Research. Retrieved 8 January, 2014 from http://digitalknowledge.babson.edu/cgi/viewconten

Hassan, N. (2006). Stress among students of the College of Education at Al-Mustansiriya University. Journal of the College of Education, second edition.

Iglesia, S., \& Azzara, S., \& Squillace, M., Jeifetz, M., Lores, A., Desimone, M., \& Diaz, L. (2005). The Relationship between Anxiety and Stress. J Anxiety Disord.Mar, 5(1), 27-31. https://doi.org/10.1080/15602210400028614

Lemons, G. (2010). A qualitative investigation of college students' creative self-efficacy. Retrieved from Pro Quest Digital Dissertation, (UMI No.3202456).

Laws, J. (2003). Self-efficacy beliefs and creative performance in adults: A phenomenological investigation. Retrieved from ProQuest Digital Dissertation (UMI No. NQ76443).

Li, Ch., \& Wu, J. (2011). The structural relationships between optimism and innovative behavior: understanding potential antecedents and mediating effects. Creativity Research Journal, 23(2), 119-128. https://doi.org/10.1080/10400419.2011.571184

Petri, H., \& Govern, J. (2004). Motivation: Theory research, and applied (4th ed.). Wadsworth: Thomson.

Phelan, S. (2001). Developing creative competence at work: The reciprocal effects of creative thinking, self-efficacy and organizational culture on creative performance. Dissertation Abstracts International, 62(2), 1059B. (UMI No. AA13003909).

Puccio, G. J., \& Cabra, J. F. (2011). Idea generation and idea evaluation: cognitive skills and deliberate practice. In: Mumford's MD (Ed.), Handbook for organizational creativity (pp. 187-213). New York: Elsevier. https://doi.org/10.1016/B978-0-12-374714-3.00009-4

Rogelio, P., \& Judith, C. (2017). Creative self-efficacy: the role of self-regulation for schoolwork and boredom as antecedents, and divergent thinking as a consequence. Soc Psychol Educ, 20, 347-359. https://doi.org/10.1007/s11218-017-9376-z

Tierney, P., \& Farmer, S. (2002). Creative self-efficacy: its potential antecedents and relationship to creative performance. Academy of Management Journal, 45, 1137-1148. https://doi.org/10.2307/3069429

Turki, J., \& Al-Qaisi, L. (2012). Adjustment problems and self-efficacy among gifted students in Salt Pioneer Center. Int J EduSci, 4(1), 1-6. https://doi.org/10.1080/09751122.2012.11890020

Yu, C. (2013). The relationship between undergraduate students' creative self-efficacy, creative ability and career self-management. International Journal of Academic Research in Progressive Education and Development, 2(2), 181-193. 